\title{
DONG-KANSAN SOITTIMISTA JA SÄVELMISTÄ
}

Suu-urku sheng • soikiokoppainen pipa-luuttu •lehdellä soittelu • dongien sävelasteikot • vertaileva kansanmusiikintutkimus Kiinassa

Joitakin tietoja dong-kansasta

Suomalainen kansanperinteen tutkimusryhmä teki matkan Kiinan Guangxin maakuntaan dong-kansan pariin huhtikuussa 1986.1 Guangxin maakunta rajoittuu lounaassa Vietnamiin, etelässä on Tonkinin lahti, idässä Guangdongin maakunta. Retkemme pääkohde, Sanjiang Dongin autonominen piirikunta sijaitsee aivan Guangxin maakunnan pohjoisosassa.

Dongit asustavat kolmen maakunnan: Guangxin, Hunanin ja Guizhoun alueella. Sinotiibettiläisten kielten thai-haaran dong shui-ryhmään kuuluvan dong-kielen puhujia on vajaa miljoona. Sanjiangin väestöstä heidän osuutensa on hiukan yli puolet (144.336/279.912) v. 1983 tilaston mukaan.

Dongien talot ovat puisia, normaalisti kolmikerroksisia rakennuksia. Alimpana asustavat kotieläimet, keskimmäisessä ovat työ- ja oleskelutilat ja ylimpänä makuutilat ja elintarvikevarastoja. Käytössä on suurperhejärjestelmä: yhdessä talossa saattaa asua useita aviopareja ja sukupolvia.

Talouden perustan muodostaa riisin ja vihannesten viljely sekä kotieläinten hoito. Myös kalanviljelyä ja metsästystä harjoitetaan. Huomiota kiinnittivät tyypilliset omavaraistalouden piirteet. Kylissä näkyi runsaasti käsityöammattien harjoittajia ja pienyrittäjiä: kyläseppiä, muita tarvekalujen valmistajia, mitä erilaisimpia kauppiaita ja kaupustelijoita, suutareita, räätäleitä, partureita jne. Markkinaelämä oli myös vilkasta. Erikoisen 
vaikutuksen teki dongien ruokakulttuuri. Ravinnoksi käytetään etupäässä tahmeaa riisiä ja erilaisia hapattamalla valmistettuja ruokalajeja: hapanlihaa, -kalaa ja -vihanneksia.

\section{Lyhyesti dongien suullisesta perinteestä}

Dongien kansanperinne heijastaa aitona ja elävänä säilynyttä, monia vanhakantaisia piirteitä sisältävää talonpoikaiskulttuuria. Suosittuja ovat lukuisat kertomusperinteen (nian) lajit, joista saimme lähinnä talletetuksi tarinoita ja kaskuja. Eniten keräsimme kuitenkin lauluperinnettä (eeppistä, lyyristä ja mm. erilaisiin rituaalitilanteisiin liittyvää laulustoa). Tallensimme miesten ja naisten, piirissä astuen esitettäviä vuorolauluja n.s. antifonisia lauluja (yetang), suurempien mies- ja naisryhmien esittämiä ryhmälauluja (yebu), lyyrisiä antifonisesti esitettyjä rakkaus- ja hälauluja (gala), lyhyitä, huilun säestyksellä esitettyjä lyyrisiä lauluja (gadi), eeppisiä ja lyyris-eeppisiä kielisoittimella säestettyjä pipa-lauluja (gapipa), muutamia yhden henkilön esittämiä työ- rituaali- ja kehtolauluja, jne. Eräs mielenkiintoisimmista perinteenmuodoista on tapasäädöksiä ja myyttisiä käsityksiä manifestoiva kuanci.2

\section{Soittimet}

Kiinassa lasketaan olevan yli 200 eri kansansoitinta. Osa niistä on paikallista alkuperää, merkittävä joukko taas kaakkoisaasialaisten kansojen yhteisomaisuutta ja osa lai nattu kaukaisemmilta kansoilta. Myös dongien soittimisto heijastaa Kiinassa vuosituhansien aikana vaikuttaneita kulttuurivirtauksia. (Ks. Malm 1967).

\section{Sheng}

Nimitystä sheng käytetään Kiinassa suu-urkuihin kuuluvista soittimista, jotka erilaisina muunnelmina ovat levinneet suureen osaan Kauko-Itää. Indokiinassa soitin tunnetaan nimellä khene, Japanissa taas on sho-niminen vastine.

Perusrakenne on eri kansojen suu-uruilla yhteinen: soitin koostuu ilmakammiosta, johon on kiinnitetty (eri kansoilla vaihteleva määrä) bambupillejä. Kammio on Lounais-Kiinassa valmistettu joko kalebassista (esim. miao ja ji-kansalla) tai bambusta (dongeilla). Dongien lusheng soittimessa on tavallisesti 6 bambupilliä, yleiskiinalaisessa shengissä niitä on 17. Kussakin pillissä on yksi sormiaukko ja sisällä on kieli (n.s. vapaa 
lehdykkä, engl. free reed). Ääni syntyy puhallettaessa ilmakammioon aukeavaan suukappaleeseen ja peittämällä sormiaukkoja, jolloin kulloinkin soitettavan pillin kieli alkaa värähdellä.

Kuva 1.

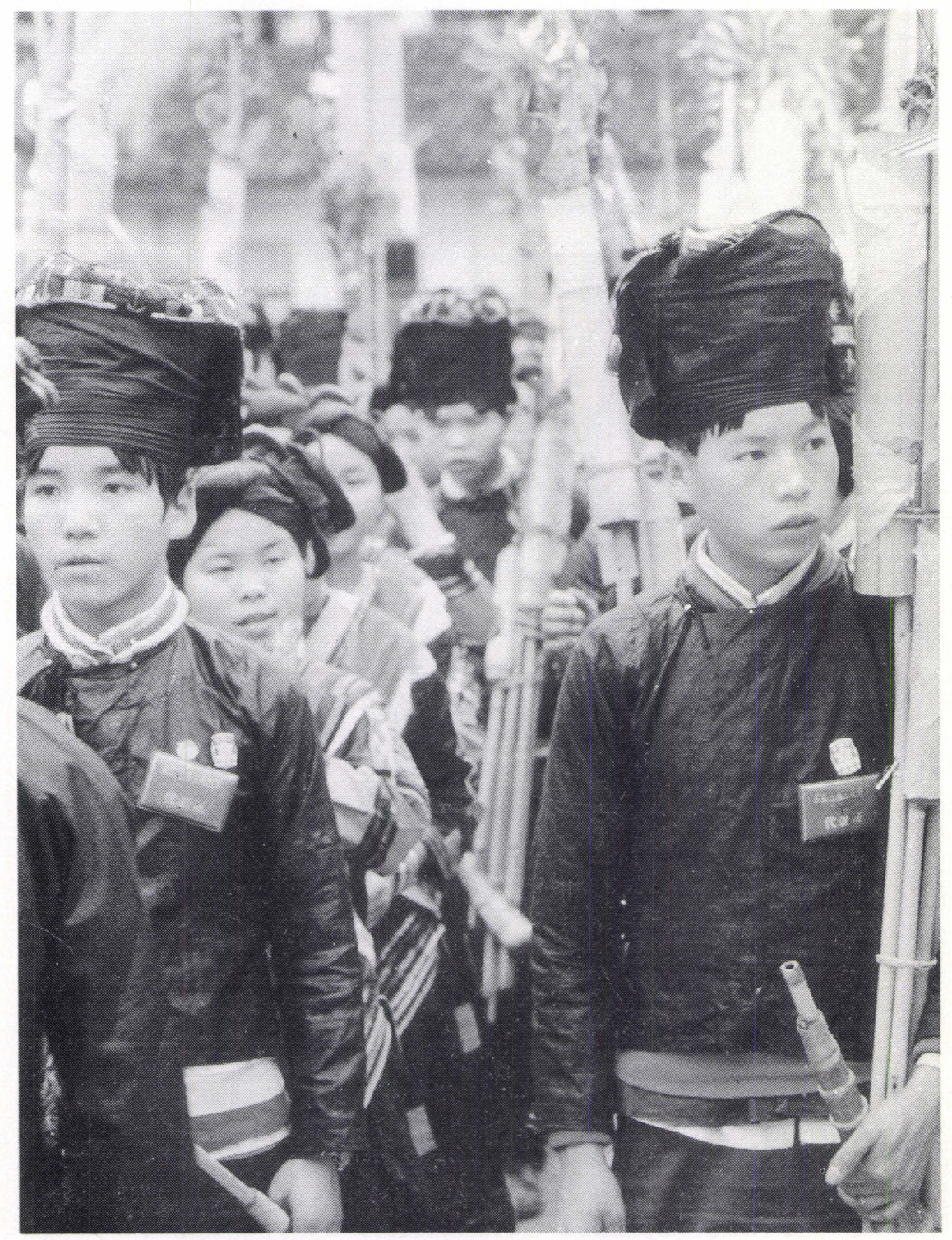

Juhlapukuista väestöä lusheng-soittimineen 
Kuva 2.

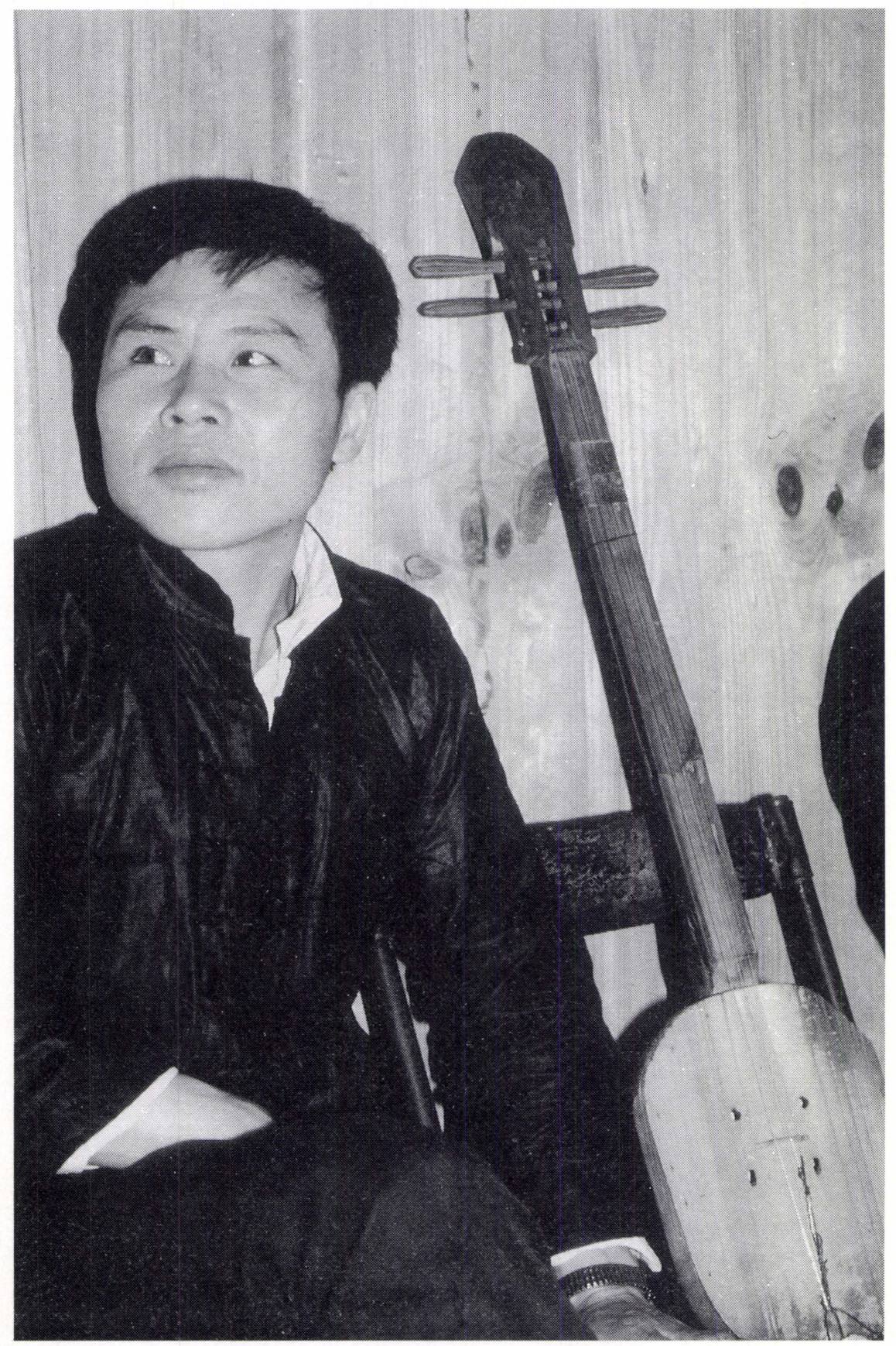

Pipa-laulaja lepotauolla. Vieressä soitin. 
Shengiä on alun perin käytetty rituaaleissa ja hovisoittimena, nyttemmin se on löytänyt tiensä myös erilaisiin kansanmusiikkikokoonpanoihin.

Vanhoissa kiinalaisissa lähteissä on mainintoja sheng-soittimesta (esim. läntisen Zhou-dynastian ajalta 1100-771 eKr.) ja sen mainitaan tulleen Kiinan alueelle Laosista. (Ks. esim. Malm 1978, s. 133-134, 185-186).

Soittimen periaatetta on sovellettu myös Euroopassa. Muun muassa harmoni, harmonikka ja huuliharppu rakentuvat vapaan lehdykän periaatteelle, samoin eräät urkupillit.

Pipa

Pipa-luutulla säestetään lähinnä kertovia lauluja. Nimityksen yhtenevyydestä huolimatta ei dongien soitin ole typologisesti kovinkaan lähellä yleiskiinalaista pipa-soitinta.

Dongien pipassa on soikiomainen kaikukoppa, pitkä kapea kaula ja neljä kieltä, joista kaksi keskimmäistä on pari kieliä. Yleiskiinalainen pipa on puolestaan kaikukopaltaan päärynänmuotoinen, leveäkaulainen soitin ja on ilmeisesti sukua arabialaiselle $u d$-luutulle. Dongien pipa onkin lähempänä eräitä muita näppäilysoittimia, joita yhdistävänä piirteenä on $\mathrm{mm}$. juuri soikea kaikukoppa ja pitkä, ohut kaula (esim. kiin. sanxian-luuttu tai japan. samisen). ${ }^{3}$

\section{Muita soittimia}

Muista soittimista mainittakoon päästä puhallettava huilu, jota käytetään yleisesti laulujen säestykseen (Wei-Hua 1985, 264-269) sekä meillä tunnettua ruokopilliä muistuttava pieni puhallinsoitin. Dongit käyttävät myös puun lehteä taidokkaasti soittimena. Jokin tankea lehti tuetaan sormin vaakasuoraan lappeelleen alahuulta vasten siten, että lehden yläreunan ja soittajan ylähuulen väliin muodostuu rako. Puhallusvoimakkuutta ja ilmavirran suuntaa säätelemällä saadaan tuotetuksi melodioita. Soittotapaa käytetään myös laulujen säestykseen.

\section{Melodiat ja asteikot}

Yksi hyvin monien kansojen vanhakantaisten laulusävelmien peruspiirre on se, että samaa tai vain vähän varioivaa melodiakaavaa käytetään tavattoman monissa eri lauluissa. Usein esiintyy myös genresidonnaisuutta, t.s. eri lajeihin tai lajiryhmiin kuuluvaa perinnettä esitetään erilaisilla perusmelodioilla. Näin on myös dongeilla. Alue- ja laulajakohtaisia eroja luonnollisesti tavataan. 


\section{Antifoniset ja ryhmälaulut}

Havaintojeni mukaan dongien sävelasteikot koostuvat 3-5 sävelestä ja ambitus on hyvin kapea. Esimerkiksi aiemmin mainittujen antifonisten- ja ryhmälaulujen asteikkoon kuuluu kolme tai neljä säveltä.

Laulut ovat yleensä esitystempoltaan verkkaisia ja sävelkukut yksinkertaisia. Melodia nojautuu 2 (joskus 3:een) pitkään säveleeseen, joita vuorotellaan. Niiden välit koostuvat nopeahkoista, ornamentointia muistuttavista kuvioista. Melodiat alkavat tavallisesti perussäveleellä. Perussävelen ohella fraasin saattaa päättää perussäveltä yhden askelen alempi sävel tai sitten säveltaso laskee äkkiä glissandonomaisesti fraasin lopussa.

Ryhmälaulussa oli suosittu myös laulutapa, jossa esilauaja aloitti resitoivalla fraasilla, jota seurasi kuoro-osuus. Laulua esitettiin rytmikkäästi piirissä astuen ja kunkin fraasin päätti ponnekas huuto.

\section{Pipa-laulut}

Kertovien pipa-laulujen skaala oli kuulemissani tapauksissa laskeva ja rakentui 5 sävelelle. Asteikko ei ollut kuitenkaan Kiinassa tavallisinta anhemitonista (puolisävelaskeletonta) pentatoniaa, vaan 1/2-sävelaskeleita käytettiin, aivan kuten esim. eräissä japanilaisissa asteikoissa.

\section{Muut laulut}

Dongien laululliseen musiikkiin kuuluvat tavallaan myös kansanomaiset lakitekstit kuanci. Niitä esitetään resitoiden ja melodinen linja muodostuu sävelkorkojen (joita dongissa on kymmenen) korosteisesta lausumisesta.

Varsinaisten dongien laulujen lisäksi tallensimme myös Kiinan pääväestölle han-kansalle sukua olevan liujia-kansallisuuden nuorten vuorolaulua. Tämä laulu perustui tavattoman voimakkaasti tuotettuun falsettiääneen. Esittäjät olivat kasvuikäisiä tyttöjä ja poikia. Laulutyyli rasitti ilmiselvästi ääntöelimistöä ja pojat poistuivat laulunsa lopetettuaan käheästi kuiskaillen paikalta.

\section{Kansanmusiikin tutkimus}

Viime vuosina (-80 lähtien) on Kiinassa järjestetty myös kansanmusiikin tutkimusseminaareja. Näissä seminaareissa pidetyistä esitelmistä heijastuu voimakas halu vertailla oman maan vähemmistökansallisuuksien musiikkikulttuureita naapurikansojen (esim. Burman, Laosin, Mongolian tai Neuvostoliiton kansallisuuksien) perinteeseen. Läheisiä yhtymäkohtia löytyy akselilla, joka ulottuu Indokiinasta Japaniin, etäisemmät yhteydet johtavat Lähi-Idän musiikkiin. Onpa esitetty teoria, jonka mukaan musiikkiasteik- 
kojen, tanssiaskeleiden, lohikäärmepiirrosten ja kalendaarijärjestelmien vertailu olisi osoituksena muinaisesta yhteydestä Kiinan ja Etelä-Amerikan välillä.7 Riippumatta siitä, kuinka rohkeita vertailuja halutaan tehdä, on Kiinan vähemmistökansojen etnomusikologinen tutkimus suuria lupauksia antava, lähes tutkimaton alue.

Kuva 3.

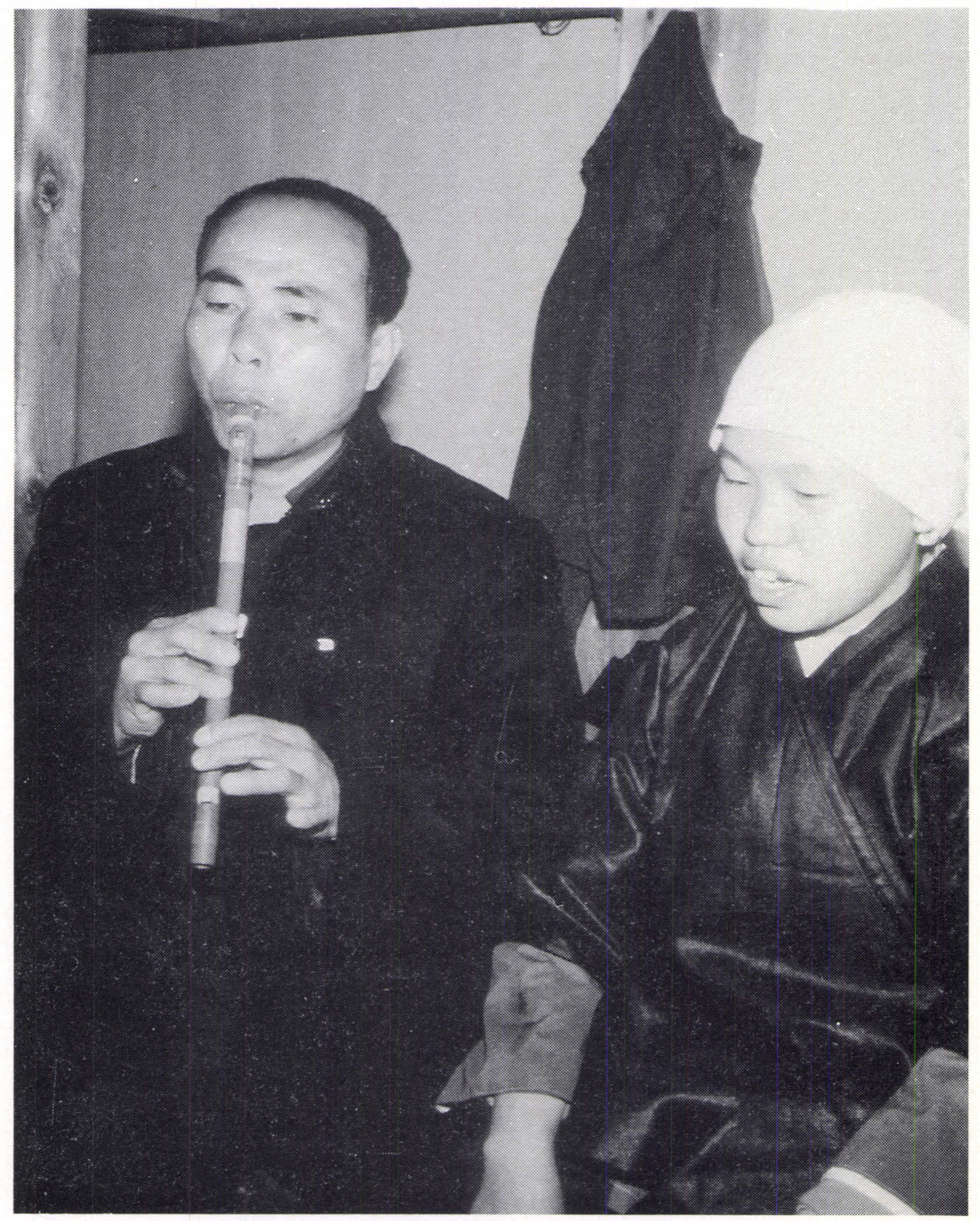

Soololaulua huilun säestyksellä. 


\section{Kuva 4.}

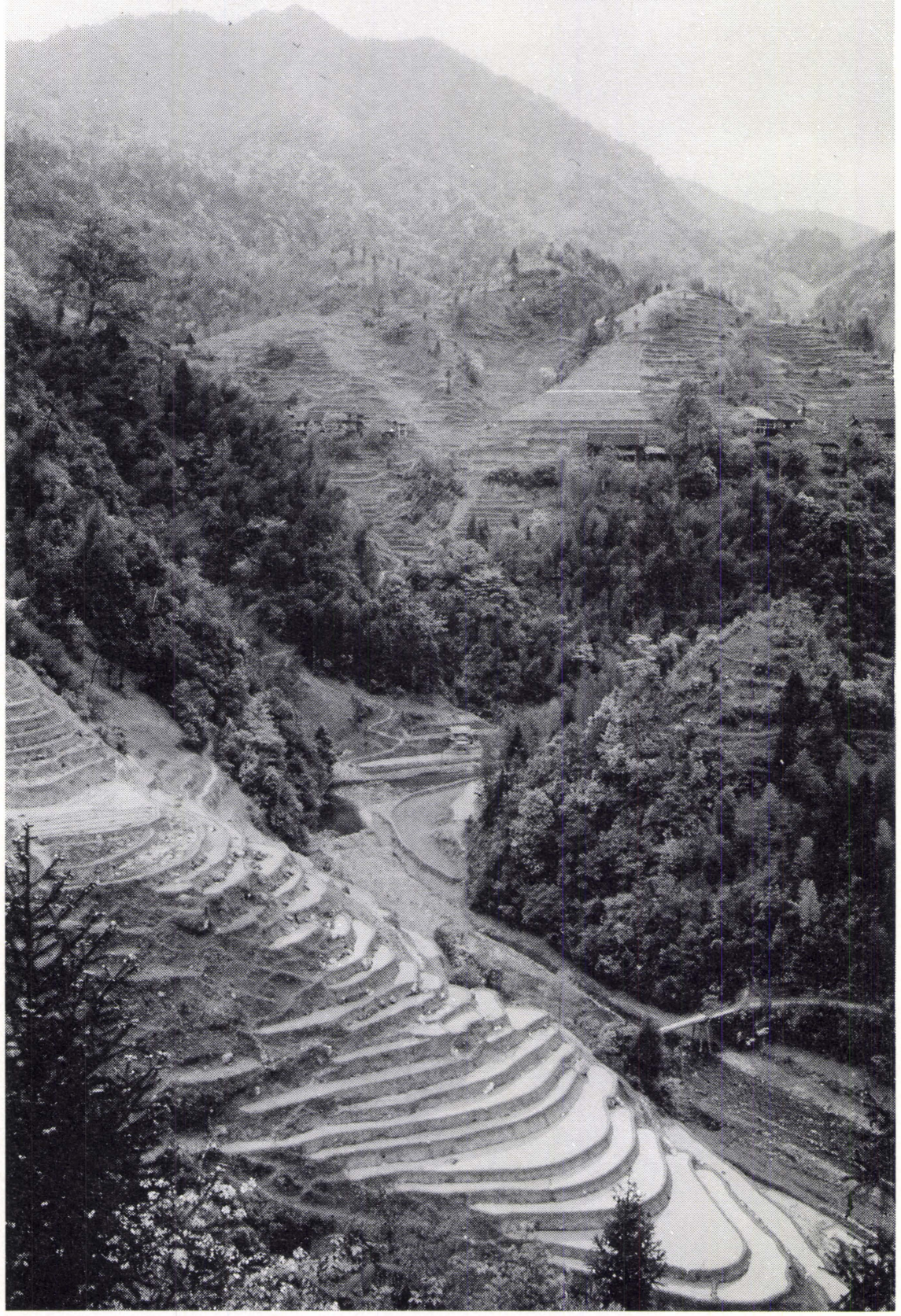

Vehmaat kukkulat ja pengerretyt riisipellot kuuluvat tyypilliseen dong-maisemaan. 


\section{Viitteet}

1. Tutkimusretkestä tarkemmin ks. Honko 1986; Harvilahti 1987.

Retkikunnan johtajana toimi professori Lauri Honko (Turun yliopisto, uskontotieteen ja folkloristiikan laitos), muina jäseninä Martti Junnonaho (Turun yliopisto, uskontotieteen assistentti), Aatos Petäjä (Turun yliopisto, av-tekniikan tuntija) sekä tämän kirjoittaja (Helsingin yliopisto, kansanrunoustieteen assistentti). Lisäksi tuli ryhmään tulkiksi Annikki Arponen Suomen Pekingin suurlähetystöstä.

Työskentely Kiinassa jakaantui kahteen osaan, joista ensimmäisen muodosti suomalais-kiinalainen kansanperinteen keruu- ja tallennusseminaari Nanningissa, maakunnan pääkaupungissa. Järjestäjien mukaan seminaari oli ensimmäinen Kiinassa järjestetty kansainvälinen tapaaminen folkloristiikan alalla. Seminaariin osallistui yhteensä 65 tutkijaa eri puolilta Kiinaa. Esitelmiä pidettiin yhteensä 25, joista kahdeksan tuli suomalaisten osalle. Seminaari oli jaettu viiteen istuntoon:

1) Yleiskatsaus kansanperinteeseen sekä folkloren suojelu

2) Perinteentutkimuksen kenttätyömenetelmät

3) Perinneaineiston säilyttäminen ja arkistointijärjestelmät

4) Folkloren luokittelujärjestelmät

5) Laaja-alainen kiinnostus kansanperinnettä kohtaan sekä perinteen julkaisutoiminta ja käyttö

2. Dongien perinteen luokittelu perustuu tässä Wu Haon ja Yang Tongshanin laatimaan ja Shi Kunin kääntämään julkaisemattomaan artikkeliin An Approach to the Classification System of the Dong Folk Literature. Tämän mukaan erotetaan kahdeksan suurta ryhmää, joista useimmat jakautuvat edelleen alalajeihin:

1) Ye - tanssien, joskus musiikin säestyksellä esitettävät laulut.

2) $G a$ - tavallisesti parisäkeiset laulut, joihin ei liity tanssia, soitinsäestys mahdollinen.

3) Nian - proosaperinteen yleisnimitys.

4) Kuan - runo- ja proosaperinne, jota ei esitetä varsinaisesti laulaen, vaan resitoiden riittitilanteissa, kansanomaisia lakitekstejä luettaessa, jne.

5) Xigeng - "Dong-ooppera", joita koostettiin runo ja proosaperinteen pohjalta Qingdynastian ajalla (1644-1911).

6) Luirenlao - kirjaimellisesti "vanhojen ihmisten sanat", millä tarkoitetaan sananlaskuperinnettä.

7) $F u$ - tarkoittaa loitsuja, taikoja, lauluja, jotka kuuluvat shamaanien (shigong) taitamaan perinteeseen.

8) Duan - arvoitukset.

3. Tämä soitin muistuttaa suuresti esim. arabien naihuilua, vrt. m. Malm 1978, s. 151152. 


\section{Lähteitä}

China Facts \& Figures (anon.): "Chinese Traditional Instrumental Music". Foreign Languages Press, Beijing 1985.

Guo Wei

1983 "Poetics of the Dong Nationality". Abstract from Journal of Nanning Teacher's College, issue 3,1983, pp. 63-68; and the last paragraph from issue 4, 1983, by the same author. Käänt. Shi Kun.

Harvilahti, Lauri

1987 "Matka dongien maille". Suomalais-Ugrilaisen Seuran aikakauskirja 81. Helsinki.

Honko, Lauri

1986 "Wooden Bells Ringing". NIF Newsletter VOL.14 2-3/1986. Turku.

Malm, William P.

1967 Music Cultures of the Pacific, the Near East, and Asia. New Jersey.

1978 Japanese Music and Musical Instruments. Rutland, Vermont \& Tokyo.

Tran Van Khe

1985 "Chinese Music and Musical Traditions of Eastern Asia" in: The World of Music/China. Intercultural Music Studies. Journal of the International Institute for Comparative Music Studies and Documentation. Vol.XXVII 1/1985. Wil helmshaven.

Zhang Wei-hua

1985 "Recent Developments of Ethnomusicology in China" in: Ethnomusicology, vol. 29, number 2/1985, Michigan.

Julkaisematon käsikirjoituksena toimitettu lähde:

Wu Hao \& Yang Tongshan

i.v. An Approach to the Classification System of the Dong Folk Literature. Käänt. Shi Kun. 